http://heanoti.com/index.php/hn

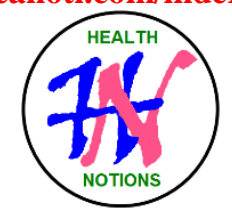

RESEARCH ARTICLE

URL of this article: http://heanoti.com/index.php/hn/article/view/hn30105

\title{
The Role of Bamboo Shoot Gigantochloa apus Extract in Decreasing MDA and Increasing IL-10 at The Atherosclerosis
}

\author{
Edy Soesanto $^{1(\mathrm{CA})}$, Edi Dharmana ${ }^{2}$, Soeharyo Hadisaputro ${ }^{2}$, Siti Fatimah Muis ${ }^{2}$ \\ ${ }^{1(\mathrm{CA})}$ Department of Nursing, Muhammadiyah University of Semarang, Indonesia; soesantoedisoes@gmail.com \\ (Corresponding Author) \\ ${ }^{2}$ Doctoral Program of Medical and Health Science, Faculty of Medicine, Diponegoro University, Indonesia; \\ edidharmana@yahoo.com \\ ${ }^{3}$ Doctoral Program of Medical and Health Science, Faculty of Medicine, Diponegoro University, Indonesia; \\ prof_haryo@yahoo.co.id \\ ${ }^{3}$ Doctoral Program of Medical and Health Science, Faculty of Medicine, Diponegoro University, Indonesia; \\ sitifatimahmuis@gmail.com
}

\begin{abstract}
Introduction: Bamboo shoot Gigantochloa apus extract has antioxidant compounds that act as lipid peroxidation inhibitors and reduce free radical formation so that it can be used as an anti-inflammatory and anti-oxidative stress in the atherosclerosis. Aim: Knowing the effect of bamboo shoot Gigantochloa apus extract in reducing MDA levels and IL-10 increasing levels in rabbits given atherogenic diet. Methods: This experiment used randomized pre-test and post-test with control group design, in 24 New Zealand White rabbits divided into 4 groups randomly. MDA and IL-10 levels were examined by the ELISA method. Results and conclusion: Bamboo shoot Gigantochloa apus extract can reduce MDA levels and increase IL-10 levels significantly in accordance with increasing doses. The increase of MDA levels in the control group with all treatment groups was different $(p=$ $0.0001)$, and between the treatment groups and other treatment groups there were also differences $(\mathrm{p}<0.05)$. The highest increase of MDA occurred in the control group (336.3\%) and the lowest was the treatment group $3(2.1 \%)$. Changes in IL-10 levels between the control group and the treatment group were significantly different $(p=$ $0.0001)$, and between treatment groups and other treatment groups there were also significant differences ( $p$ $<0.05)$. All groups experienced a decrease in IL-10 levels except in treatment group 3 experiencing an increase of $58.7 \%$ and the highest decrease occurred in the control group (64.3\%). Bamboo shoot Gigantochloa apus extract effect on decreasing MDA levels and increasing levels of IL-10
\end{abstract}

Keywords: Bamboo shoot, MDA, IL-10

\section{INTRODUCTION}

The community lifestyle is strongly influenced by the times, it can be seen from the diet, saturated fat consumption and daily activities. This can lead to the emergence of several diseases such as cardiovascular disease. Heart and blood vessels disease caused by atherosclerosis as the cause of death in Indonesia reached $5.1 \%$ of all deaths in all age groups and increased to $8.7 \%$ in the age range 45-54 years and the increased incidence of atherosclerosis in patients aged more than 40 years of $17-40 \% .^{(1)}$ Oxidized LDL leads to endothelial dysfunction and inflammatory processes leading to atherosclerosis. ${ }^{(2)}$ Endothelial dysfunction will decrease the synthesis of nitric oxide, increase endothelin levels and oxygen-free radical formation and trigger the release of proinflammatory and anti-inflammatory cytokines. ${ }^{(3)}$

The use of bamboo shoot Gigantochloa apus as anti-inflammatory drugs and oxidative stress has long been used widely in almost all countries in the world. ${ }^{(4,5)}$ The anti-inflammatory and oxidative effects of bamboo shoots are suspected to contain antioxidants that can work as free oxygen captains, free hydroxyl, inhibiting lipid peroxidation and reducing the formation of free radicals formed by LDL oxidation. The flavonoid content of bamboo shoots is also thought to have an anti-inflammatory role, by inhibiting the proliferation phase and the exudation phase of the inflammatory process, inhibiting the release of arachidonic acid and lysosomal enzyme secretion from neutrophil and endoteil cells by blocking the path of cyclooxygenation, lipoxygenation pathway 
and phospholipase. ${ }^{(6)}$ Therefore, it is necessary to do further research in order to know the potential of bamboo shoots in preventing atherosclerosis through decrease of oxidative stress and inflammatory marker in the process of atherosclerosis with the meter decrease of MDA level, and increase of IL-10 level.

\section{METHODS}

This was a pure experimental study, with a randomized pre and post test with control group design in the New Zealand White rabbits. The subjects were divided into 4 treatment groups in simple random sampling, observed for 90 days then the results before and after treatment were compared each other. The place of this experiment held in Integrated Research and Testing Laboratory Gadjah Mada University, Yogyakarta, Indonesia, from Juli to September 2017.

The sample of this study was the New Zealand White rabbits obtained from the Animal Experimental Development Unit, Gajah Mada University, Yogyakarta. The mode of selection was adjusted to inclusion and exclusion criteria with $n=24$ and each group being 6 rabbits. Group $1=$ control group (atherogenic diet), group 2 = treatment group 1 (atherogenic diet with bamboo shoot Gigantochloa apus kurz extract $130 \mathrm{mg} / \mathrm{kg} \mathrm{BW}$ ), group 3 = treatment group 2 (atherogenic diet with bamboo shoot Gigantochloa apus kurz extract $260 \mathrm{mg} / \mathrm{kg}$ BW), and group 4 = treatment group 3 (atherogenic diet with bamboo shoot Gigantochloa apus kurz extract 520 $\mathrm{mg} / \mathrm{kg} \mathrm{BW}$ ). Levels of interleukin 10 (IL-10) and Malondialdehyde (MDA) were examined using quantitative sandwich enmyme immunoassay (ELISA). Statistical data processing using one way Anova followed by post hoc LSD.

Malondialdehyde (MDA)

\section{RESULTS}

Table 1. The levels of Malondialdehyde ( $\mu \mathrm{mol} / \mathrm{l})$

\begin{tabular}{llllll}
\hline Treatment & \multicolumn{1}{c}{$\mathrm{C}$} & \multicolumn{1}{c}{$\mathrm{T} 1$} & \multicolumn{1}{c}{$\mathrm{T} 2$} & $\mathrm{~T}$ & $\mathrm{p}^{1}$ \\
\hline Before & $71.1 \pm 84.09^{\mathrm{a}}$ & $86.6 \pm 48.96^{\mathrm{a}}$ & $126.9 \pm 41.87^{\mathrm{a}}$ & $109.5 \pm 38.06^{\mathrm{a}}$ & 0.395 \\
After & $310.2 \pm 106.81^{\mathrm{a}}$ & $201.8 \pm 51.92^{\mathrm{b}}$ & $189.5 \pm 50.38^{\mathrm{b}}$ & $107.2 \pm 53.20^{\mathrm{b}}$ & 0.0001 \\
\hline Deviation $\Delta$ & $239.1 \pm 36.26$ & $115.2 \pm 17.69$ & $62.6 \pm 11.48$ & $-2.3 \pm 44.25$ & 0.0001 \\
\hline
\end{tabular}

1 The $\mathrm{p}$-value of the Anova test results on the same line

a,b The same letter in a row shows no significant difference between treatments (Anova test, $\mathrm{p}>0.05$ ).

The mean total of Malondialdehyde levels of the sample before treatment was $93.6 \pm 33.6 \mathrm{ng} / \mathrm{mL}$ with interval between 34.7-167.2 $\mathrm{ng} / \mathrm{mL}$. The mean total of Malondialdehid levels of the sample after treatment was $190.5 \pm 79.5 \mathrm{ng} / \mathrm{mL}$ with interval between 30.0-353.9 ng / $\mathrm{mL}$. Based on the data in Table 1, there was an increase in the levels of Malondialdehyde in all groups, except in the treatment group 3 which decreased by $2.1 \%$. The highest increase occurred in the control group (336.3\%).

In the pre-test, the mean of Malondialdehyde levels was done by one way Anova $(p=0.353)$, it means that the level of Malondialdehyde between treatments was same, then the difference test was done in post-test $(\mathrm{p}=$ 0.001), it mean that the level of Malondialdehyde between treatments was different. Post-hoc LSD test showed that the mean of Malondialdehyde levels increasing rate in the control group was significantly different with the treatment group $(\mathrm{p}<0.05)$, the control group with the treatment group 1 was significantly different $(\mathrm{p}=0.014)$, the control group with the treatment group 2 significantly different $(\mathrm{p}=0.007)$, and the control group with treatment group 3 was significantly different $(\mathrm{p}=0.0001)$.

The highest mean of Malondialdehyde levels increasing rate was $269.56 \mathrm{ng} / \mathrm{mL}$ and the lowest was -62.72 $\mathrm{ng} / \mathrm{mL}$. Increased levels of Malondialdehyde control group with treatment group 1, 2 and 3 were significantly different $(\mathrm{p}=0.0001)$, and between treatment group and other treatment group there was also significantly different $(\mathrm{p}<0.05)$. Thus this research prove that there wass a decrease of Malondialdehyde levels after giving bamboo shoot Gigantochloa apus kurz extract in various doses, thus giving bamboo shoot Gigantochloa apus kurz extract have influence to decrease of Malondialdehyde rate.

In this study showed that the difference $\Delta$ highest increase of Malondialdehid (MDA) occurred in the control group that was $212.4 \pm 36.26 \mathrm{ng} / \mathrm{mL}$ and the lowest was treatment group 3 was $-2.34 \pm 44.25 \mathrm{ng} / \mathrm{mL}$. Increased number of Malondialdehyde between control group with treatment group 1, 2 and 3 there was significantly different $(\mathrm{p}=0.0001)$, and between treatment group and other treatment group was also significantly different $(\mathrm{p}<0.05)$. The cells in the body continuously produce free radicals as part of the metabolic process of high-lipid feeding. Free radicals can increase due to the accumulation of lipids in the body and can increase the process of oxidation of long-chain saturated fatty acids (Polyunsaturated Fatty Acid / PUFA) to form MDA. ${ }^{(7)}$

\section{Interleukin (IL)}

The mean of IL-10 levels of all samples before treatment was $2402.7 \pm 736.3 \mathrm{pg} / \mathrm{mL}$ with interval between 992.8-4150.8 pg / mL. The mean of IL-10 levels of all samples after treatment was $1990.72 \pm 1094.72 \mathrm{pg} / \mathrm{mL}$ with interval between $616.8-4354.8 \mathrm{pg} / \mathrm{mL}$. In the pre-test, the mean of IL-10 level was performed by different 
test with one way anova got significant result $(\mathrm{p}=0.0001)$ meaning that the IL-10 levels between treatments was different, then the difference test was done on delta $\Delta,(\mathrm{p}=0.0001)$. Post-hoc LSD test showed that the mean rate of change in randomized IL-10 levels in the control group was significantly different from the treatment group (p $<0.05)$, the control group with treatment group 1,2 and 3 was significantly different $(\mathrm{p}=0.0001)$, treatment group 1 with treatment group 2 and 3 were significantly different $(\mathrm{p}=0.028$ and $\mathrm{p}=0.0001)$.

Table 2. Mean levels of Interleukin 10 (pg/mL)

\begin{tabular}{lccccl}
\hline Treatment & $\mathrm{C}$ & $\mathrm{T} 1$ & $\mathrm{~T} 2$ & $\mathrm{~T} 3$ & $\mathrm{p}^{1}$ \\
\hline Before & $3396.1 \pm 342.81^{\mathrm{a}}$ & $3913.8 \pm 707.19^{\mathrm{a}}$ & $2278.5 \pm 926.49^{\mathrm{a}}$ & $2022.5 \pm 715.72^{\mathrm{a}}$ & 0.0001 \\
After & $1211.8 \pm 339.26^{\mathrm{a}}$ & $3012.5 \pm 737.60^{\mathrm{a}}$ & $1829.8 \pm 901.52^{\mathrm{a}}$ & $3208.8 \pm 966.35^{\mathrm{a}}$ & 0.002 \\
\hline Deviation $\Delta$ & $-2184.3 \pm 466.12^{\mathrm{a}}$ & $-901.3 \pm 132.78^{\mathrm{a}}$ & $-448.7 \pm 159^{\mathrm{a}}$ & $1186.3 \pm 441.81^{\mathrm{a}}$ & 0.0001 \\
\hline
\end{tabular}

1 The p-value of the Anova test results on the same line

$\mathrm{a}, \mathrm{b}$ The same letter in a row indicates there is a marked difference between treatments (Anova test, $\mathrm{p}<0.05$ ).

The highest mean change of IL-10 levels was $1484.3 \mathrm{pg} / \mathrm{mL}$ and the lowest was $-1186.3 \mathrm{pg} / \mathrm{mL}$. Changes in IL-10 levels between the control group and the treatment group were significantly different $(\mathrm{p}=0.0001)$, and between treatment groups and other treatment groups there was also a significantly different ( $\mathrm{p}<0.05)$. Based on the data in Table 2, all groups experienced a decrease in IL-10 levels, except in treatment group 3 which experienced an increase of $58.7 \%$ and the highest decrease occurred in the control group of $62 \%$. Thus, this study prove that there was an increase of interleukin-10 levels after giving bamboo shoot Gigantochloa apus kurz extract in various doses, thus giving bamboo shoot Gigantochloa apus kurz extract has an effect on the increase of interleukin-10 level, the higher the dosage of bamboo shoot Gigantochloa apus kurz extract will increase the level interleukin-10 in the blood (dose effect relationship).

In the LSD post-hoc test, the mean rate of change in the IL-10 levels in the control group was significantly different with the treatment group ( $\mathrm{p}<0.05$ ), all groups experienced a decrease in IL-10 levels especially in the control group and except in the 3rd treatment group experienced an increase. The difference between the highest levels of IL-10 occurred in the control group of $-2184.3 \pm 466.12 \mathrm{pg} / \mathrm{mL}$ or $62 \%$ and the highest increase of IL10 levels occurred in treatment group 3 of $1186.33 \pm 441.81 \mathrm{pg} / \mathrm{mL}$ or $58.7 \%$.

\section{DISCUSSION}

\section{Maldialdehyde (MDA)}

This study also proved that the hyperlipid feeding can increase free radical which is indicated by the increase of MDA level equal to 291.8\% and the higher dosage of bamboo shoot Gigantochloa apus kurz extract given can effectively push the formation of MDA. High levels of MDA in serum are an indication of oxidation activity, a marker of cellular damage due to free radicals and biologic markers of oxidative stress. ${ }^{(8,9)}$ The higher the lipid intake the easier it will be to oxidize stress because there is an imbalance in the amount of antioxidants in the body with excessive oxidant levels and lipids have a double carbon chain which is very easy to react with oxidants to produce lipid hydroperoxidation as a result of the lipid peroxidation process. Lipid hydroperoxide has an unstable structure and is easily converted to MDA, and some other aldehyde forms. ${ }^{(7)}$ Free radicals are also able to react by injuring arterial endothelium cells and smooth muscle cells within the blood vessel wall by preventing macrophages from phagocytosis and promoting the formation of large fagocyte foam cells containing cholesterol plaque. ${ }^{(6)}$

The body has a mechanism to decrease free radicals by using endogenous antioxidants such as catalase enzymes that bind to $\mathrm{Fe}$, superoxide dismutase binding to $\mathrm{Cu}, \mathrm{Zn}$ and $\mathrm{Mn}$, glutathione peroxidase and glutathione S-transferase binding to Se. ${ }^{(10)}$ However, because of the excessive intake of lipids can induce many free radicals that eventually can not be overcome by natural mechanisms of endogenous antioxidants. To minimize the effects of oxidative stress, in this study the exogenous antioxidant intake was bamboo shoots containing palmitic acid, curcumene, limonene, toluene, naphthalene, 1,3,5-trimethyl benzene, vitexin, orientin and vitamin $\mathrm{C}$, vitamin $\mathrm{E}$ and fibers that can reduce oxidative stress. ${ }^{(11)}$

This research also showed that giving of bamboo shoot Gigantochloa apus kurz extract with dose $520 \mathrm{mg}$ / kg BW able to decrease MDA level 2.18\%, this happened because of antioxidant in bamboo extract which inhibit lipid peroxidation process. The bamboo shoot gigantochloa apus kurz extract inhibits lipid peroxidation by capturing free radicals and donating the hydrogen atom to form a more stable compound and stopping the lipid peroxidation chain reaction. LDL oxidation in atherosclerotic lesions is inhibited by secreting VCAM-1 in the endothelium, reducing oxidized LDL toxicity to endothelial cells, smooth muscle cells and macrophages, reducing oxidative degradation due to nitric oxide, limiting vasoconstriction and reducing blood pressure.

The mechanism of action of antioxidants in inhibiting the process of oxidation of fat in the body can occur through reactions, release of hydrogen from antioxidants, electron release from antioxidants, fat addition into aromatic rings on antioxidants, the formation of complex compounds between fat and aromatic rings of 
antioxidants. ${ }^{(10)}$ Antioxidant compounds contained in bamboo shoots have antioxidant and anti-inflammatory activity to prevent serum MDA elevation. Bamboo shoots contains anions (negative ions) having density reaches $6000 \mathrm{bh} / \mathrm{m} 3$, negative ions are ions that have oxygen content, colorless and tasteless. This ion serves to provide adequate oxygen intake for our bodies. Antioxidant effects on bamboo extract as free oxygen and free hydroxyl capture can inhibit the occurrence of lipid peroxidation. ${ }^{(12)}$

The content of vitamin $\mathrm{C}$ in bamboo shoots can reduce the levels of MDA by giving electrons in free radicals so it will be stable, capture superoxide radicals and singlet oxygen and break the radical chain produced by lipid peroxidase. The antioxidative activity of flavonoids stems from the ability to donate its hydrogen atom or through its ability to engage metals. Plavonoid content in bamboo shoots is thought to be able to reduce intracellular ROS by binding to one free radical which then bonds will be able to stabilize the peroxy that makes synergy activation will be reduced, consequently will inhibit oxidation reaction from LDL cholesterol. ${ }^{(6)}$ These barriers will be able to reduce LDL oxidation, where decreased LDL oxidation will inhibit NF-kB activation, so there will be a decreased level of cytokines in circulation. ${ }^{(13)}$

Flavonoids are anti-heterogeneous inhibiting LDL oxidation so that vascular endothelial integrity is maintained and able to reduce the risk of atherosclerosis. The content of polyphenol compounds, $\mathrm{C}$-glucosides and p-coumaric acid in bamboo shoots is an antioxidant compound that captures superoxide and hydroxyl radicals and inhibits lipid peroxidation. In addition to plavonoid content of water-soluble fiber in bamboo shoots can reduce LDL by binding fatty acids, cholesterol and bile salts so it can not form micelles in the gastrointestinal tract, consequently fat can not be absorbed and excreted through the feces. Fiber also binds bile salts so that they can not be reabsorbed and recirculated through the enterohepatic cycle, then discharged through the feces. Fiber also reduces serum cholesterol levels by the mechanism of shifting bile acid pathway from cholic acid to chenodeocycolic acid thereby decreasing HMG CoA activity.

Other studies have also shown that there is a relationship between increased MDA as a result of oxidative stress on the formation of atherosclerosis. ${ }^{(14,15,16)}$ MDA concentration is used as an indicator and oxidative damage to unsaturated fats as well as an indicator of the presence of free radicals. Thus, it can be concluded that high levels of MDA indicate in cell membranes occur oxidation process and high levels of antioxidants in the body is usually followed by a decrease in MDA levels. MDA levels will be more common in rabbits who consume more fat-containing foods because of the possibility of stored fat as energy reserves are also increasing so that the chances of lipid peroxide and MDA confidence are also higher.

\section{Interleukin-10 (IL-10)}

Atherosclerosis is a chronic inflammatory condition in artery walls characterized by accumulation of lipids, progressive cells (macrophages, lymphocytes, and smooth muscle cells), and extracellular matrix. ${ }^{(17)}$ Of the cells participating in atherogenesis, macrophages derived from monocytes and $\mathrm{T}$ lymphocytes are the most prominent cells that secrete various pro- or anti-atherogenic cytokines that can affect disease progression and affect plaque stability. As the most abundant type of inflammatory cells in plaque, macrophages are the most important source of cytokine production (pro-inflammatory and anti-inflammatory) in atherosclerotic lesions, pro-inflammatory can promote the development of atherosclerosis. ${ }^{(18)}$ While anti-inflammatory cytokines such as IL-10 can have anti-atherogenic effects. IL-10 is produced by various inflammatory cells primarily by macrophages and $\mathrm{T}$ lymphocytes from the Th2 subtype, therefore can be produced locally in atherosclerotic lesions. The major functions of IL-10 as an anti-inflammatory (athero-protective) effect include inhibition of macrophage activation as well as inhibition of metalloproteinase matrices (MMPs), proinflammatory cytokines, cyclooxygenase-2 expression, induces mast cell proliferation, B and T lymphocytes, and increases response T cells against IL-2. ${ }^{(19)}$

This study shows that the higher bamboo shoot Gigantochloa apus kurz extract diet will increase the levels of IL-10 (diet of bamboo shoot Gigantochloa apus kurz extract 520 mg / Kg BW / day can increase the levels of IL 10 by $58.7 \%$ ). Increased serum IL-10 levels are a favorable prognostic determinant in patients with acute coronary syndromes. The expression of IL-10 by macrophage plaque limits the inflammatory response and promotes plaque healing by inhibiting IL-12 and the production of nitric oxide synthase. IL-10 also attempts to deplete atherogenic lesions by inhibiting the release of some pro-inflammatory cytokines (including IL-1, TNF$\alpha$, IL-8 and IL-17) of monocyte cells, and to induce the production of IL-1 receptor antagonists. IL-10 induced inhibition of MCP-1 in monocyte recruitment at the onset of atherosclerotic lesions has been considered an important protective mechanism of atherogenesis by IL-10 ${ }^{(19,20)}$ IL-10 has a protective effect on plaque rupture and thrombus formation. Decreased collagen synthesis and increased metalloprotein activity lead to fibrous crust and fibrousness. Therefore, low levels of IL-10 may lead to increased MMP activity which in turn may induce plaque instability causing acute cardiovascular events in certain individuals. ${ }^{(19)}$ IL-10 can protect atherosclerotic plaques from excessive cell damage and death by inhibiting iNOS production and inhibit the production of reactive oxygen that results in LDL oxidation.

The imbalance between pro and anti-inflammatory forces affects plaque disturbance and recurrent cardiovascular events with a shift toward Th1 dominance seen in atherosclerotic patients. To support this concept is a report that the ratio between IL-18 and IL-10 serum is an independent predictor of adverse events in hospitals 
in patients with acute coronary syndromes, since IL-10 is a better prognostic marker than inflammatory markers such as CRP and IL- 18 to predict cardiovascular events in ACS patients. ${ }^{(21)}$ There is an inverse correlation between pro-inflammatory CRP and anti-inflammatory IL-10 levels in patients with atherosclerosis. Thus, the application of bamboo shoot Gigantochloa apus kurz extract can increase the levels of IL-10 in the blood.

\section{CONCLUSION}

The administration of Bamboo Shoot Gigantochloa apus extract in various doses was able to influence oxidative stress and inflammatory processes in New Zealand White rabbits who were given an atherogenic diet for 90 days. There was a significant decrease in MDA levels and a significant increase in IL-10 levels in all treatment groups compared to the control group. The status of oxidative stress with parameters of MDA levels and inflammatory status with IL-10 parameters can be reduced or inhibited by the administration of Bamboo Shoot Gigantochloa apus extract of $520 \mathrm{mg} / \mathrm{kgBW} /$ day.

\section{REFERENCES}

1. MoH. Guidelines for Controlling Heart and Blood Vessel Disease. Jakarta: Ministry of Health of the Republic of Indonesia; 2010.

2. Li D, Mehta JL. Oxidized LDL, A Critical Factor in Atherogenesis. Cardiovascular Research. 2005;68:353354.

3. Brodziak, Brewczyński. Environmental Factors Influencing the Development of Atherosclerosis. Environmental Medicine. 2013;16 (4):7-15

4. Chongtham N, Bisht MS, Haorongbam S. Nutritional Properties of Bamboo Shoots: Potential and Prospects for Utilization as a Health Food. Comprehensive Reviews in Food Science and Food Safety. 2011;10(3):15368.

5. Soesanto E. Analysis Proximate, HCN, Antioxidant Compounds and Antioxidant Activities of Potential Extract as Antiatherosclerosis. Media Keperawatan Indonesia. 2018;1(3):32-45.

6. Sabir A. In Vitro Antibacterial Activity of Flavonoids Trigona Sp Propolis Against Streptococcus Mutans. Dental Journal. 2005;38(3):135-41.

7. Ayala A, Muñoz MF, Argüelles S. Lipid Peroxidation: Production, Metabolism, and Signaling Mechanisms of Malondialdehyde and 4-Hydroxy-2-Nonenal. Oxidative Medicine and Cellular Longevity. 2014;1-31.

8. Werdhasari A. The Role of Antioxidants for Health. Indonesian Medical Biotech Journal. 2014;3(2):59-68.

9. Singh Z, Karthigesu Ip, Singh P, Kaur R. Use of malondialdehyde as a Biomarker for Assessing Oxidative Stress in Different Disease Pathologies: a Review. Iranian J Publ Health. 2014;43(Suppl. 3):7-16.

10. Sayuti K, Yenrina R. Natural and Synthetic Antioxidants. Padang: Andalas University Press;2015.

11. Lu B, Xia D, Huang W, Wu X, Zhang Y, Yao Y. Hypolipidemic Effect of Bamboo Shoot Oil (P. pubescens) in Sprague-Dawley Rats. Journal of Food Science. 2010;75(6).

12. Lu B, Wu X, Shi J, Dong Y, Zhang Y. Toxicology and Safety of Antioxidant of Bamboo Leaves. Part 2: Developmental Toxicity Test in Rats with Antioxidant of Bamboo Leaves. Food and Chemical Toxicology. 2006;44(10):1739-43.

13. Grassi D, Desideri G, Croce G, Tiberti S, Aggio A, Ferri C. Flavonoids, Vascular Function and Cardiovascular Protection. Current Pharmaceutical Design. 2009;15(10):1072-84.

14. Soydinc S, Celik A, Demiryürek S, Davutoğlu V, Tarakçıŏlu M, Aksoy M. The Relationship between Oxidative Stress, Nitric Oxide, and Coronary Artery Disease. European Journal of General Medicine. 2015;4(2):62-6.

15. Soesanto, Khoiriyah. Effectiveness of Apus Bamboo Shoots Extract on the Reduction of MDA Levels in Hypercholesterolemic New Zaeland White Rabbits. Journal. Unimus. 2017;131-35.

16. Ayala, Muñoz, Argüelles. Lipid Peroxidation: Production, Metabolism, and Signaling Mechanisms of Malondialdehyde and 4-Hydroxy-2-Nonenal. Oxidative Medicine and Cellular Longevity. 2014;1-31.

17. Libby P. Inflammation in Atherosclerosis. Arteriosclerosis, Thrombosis, and Vascular Biology. 2012;32(9): 2045-51.

18. Little PJ, Chait A, Bobik A. Cellular and Cytokine-Based Inflammatory Processes as Novel Therapeutic Targets for the Prevention and Treatment of Atherosclerosis. Pharmacology \& Therapeutics. 2011;131(3):255-68.

19. Han X, Boisvert WA. The Role of IL-10 in Atherosclerosis. Atherogenesis: InTech. 2012;361-84.

20. Han X, Kitamoto S, Wang H, Boisvert WA. Interleukin-10 Overexpression in Macrophages Suppresses Atherosclerosis in Hyperlipidemic Mice. The FASEB Journal. 2010;24(8):2869-80.

21. Chalikias GK, Tziakas DN, Kaski JC, Hatzinikolaou EI, Stakos DA, Tentes IK, et al. Interleukin-18: Interleukin-10 Ratio and in-Hospital Adverse Events in Patients with Acute Coronary Syndrome. Atherosclerosis. 2005;182(1):135-43. 